\title{
Comparing the Performance of ESL and English-Native Speaking Students in an Introductory Level Statistics Course
}

\author{
Hend Aljobaily $^{1, *}$, Austin Brown ${ }^{1}$, Bryce Whitehead ${ }^{1} \&$ Kofi Wagya $^{1}$ \\ ${ }^{1}$ University of Northern Colorado, Campus Box 28, 501 20th St, Greeley, CO 80639, USA \\ *Correspondence: University of Northern Colorado, Campus Box 28, 501 20th St, Greeley, \\ CO 80639, USA. E-mail: hend.aljobaily@unco.edu
}

Received: March 25, 2019 Accepted: January 20, 2020 Published: February 14, 2020

doi:10.5296/ije.v12i1.14549 URL: https://doi.org/10.5296/ije.v12i1.14549

\begin{abstract}
English as a second language (ESL) students often face more challenges than their English-Native Speaking (ENS) peers due to language and cultural barriers. The purpose of this study is to investigate the difference in performance between ESL students and ENS students in the introductory level statistics course, STAT150, at the University of Norther Colorado (UNC). Due to the dichotomous nature of the data and the large differences in sample sizes between ESN and ESL students, the Bootstrapped Logistic Regression model is used to analyze the data. Contrary to the findings of previously conducted studies, the results of this study suggest that ESL students who have been enrolled in STAT 150 at UNC are just as likely to receive a high mark in the course as their ENS counterparts. One explanation for this finding is that the level of instruction and quality of content provided throughout the course gave all students, including ESL students, all the information necessary to succeed in the course. If this explanation is accepted, the outcomecentric results found by this study reflect well upon the overall quality of instruction and English proficiency policies at UNC.
\end{abstract}

Keywords: ESL students, ENS students, mathematics, statistics class, comparing, performance, education, bootstrapping 


\section{Introduction}

Mathematics is of unique importance in education because it can be used to teach students logic in a way no other educational discipline can. The cognitive exercises required to learn mathematics give students the skills necessary to succeed in other sciences. Consequently, the teaching of mathematics, especially at the elementary level, is of fundamental importance to students who pursue higher education in a scientific field. The teaching of mathematics aims to cultivate the development of functional cognitive reasoning in students. This is achieved by improving the students' understanding of mathematical concepts, their computational accuracy, and the speed at which they can solve problems.

Mathematics is a language. While not a natural human language, its usage of symbols and logic can be learned and understood by people regardless of their native tongue. As is the case with natural languages, the language of mathematics is best taught through the utilization of practice and repetition. Many of the concepts that students encounter when learning mathematics are quite alien and require the development of new ways of thinking. Other mathematical concepts employ the use of technical terms that have a different meaning than or are similar to words used in everyday speech. These language overlaps can cause confusion in students becoming familiar with mathematical language (Meiers \& Trevitt, 2010). Each subject area has its own methods of using language to construct knowledge, and students need to gain an understanding of this use of language in order to establish a strong understanding of the subject. Students who exhibit difficulties with receptive and/or expressive language skills during typical communication may reasonably be expected to have difficulties in understanding mathematical language and are likely to experience broader academic challenges.

In mathematically based classes, instructors may have an erroneous assumption that students for whom English is their second language (referred to as "English as Second Language (ESL) students") will have a minimal disadvantage as these classes are numerically oriented and are not heavily dependent on English. According to Ewing and Huguelet (2009), the language of mathematics is comprised of the discussion of equations, the explanation of word problems, and the use of jargon. The disadvantage lies in the fact that, as the authors note, the language of math is rarely included in the curriculum of any ESL programs or English as a foreign language (EFL) programs (2009). This lack of connection between ESL programs and math language results in students struggling academically in introductory college-level math-based courses (2009). As mentioned, one type of difficulty ESL students enrolled in math-based courses may face are jargon problems. ESL students may also struggle understanding key words and phrases in word problems. Additionally, they may face difficulties identifying cultural references within mathematical problems. Moreover, ESL students may have trouble articulating solutions for word problems, even when they understand all the relevant mathematical vocabulary (2009).

It has been shown that ESL students have historically had lower academic performance in mathematics than their native English-speaking peers (Abedi et al., 2006). The literature suggests that this performance gap is explained by parental education level, poverty, and the challenge of second language acquisition (Hakuta, Butler, \& Witt, 2000; Redd, et al., 2002). 
However, there is also evidence to suggest that in situations when ESL students are provided with sufficient content and skills delivered by proficient math instructors in a classroom of students who are proficient in math, they show improvement in mathematical knowledge and skills (Abedi et al., 2006).

\section{Literature Review}

\subsection{The Importance of Diversity in Higher Education Classrooms}

Recently, colleges and universities have become interested in the importance of creating a diverse environment on campus. Enrolling more international students for whom English is not their first language has been one way that these campuses have tried to achieve this goal. Research suggests that a diverse classroom at a higher education institution enhances all students' active learning and intellectual engagement abilities (Gurin et al., 2002). However, an ESL student who is pursuing a degree in higher education within an English-speaking institution may face many challenges. Some of these challenges include cultural adaptation, academic adaptation, and finding a communication system (Al-jamal \& Miqdadi, 2013). Because of these challenges faced by ESL students in higher education, teaching science and math classes with ESL students at a college-level requires different approaches to ensure that all students get the appropriate education (Nelson, 1996).

\subsection{Struggling ESL Students with Math Word Problems}

While mathematics is considered a universal language, it needs to be learned which makes it more difficult for students in introductory math courses to fully understand (Moschkovich, 2012; Langeness, 2011). It has been suggested that a substantial part of the struggle that ESL students experience in math courses is due to their limited mathematical vocabulary (Krick-Morales, 2017). Research has shown that ESL students tend to perform well in classes that are not based on writing (Finn, 2018). ESL students who have an average skillset in mathematics tend to do well in numberbased problems due to their understanding of the mathematical symbols that are shared worldwide (Krick-Morales, 2017). Unfortunately, part of the challenge an ESL student faces in a college-level math course is understanding what particular questions are asking them to do (KrickMorales, 2017). Some studies have suggested that ESL students could perform better in word problems if they were introduced to the vocabulary before starting a problem (Moschkovich, 2012). ESL students must be given the information needed to understand the problem, model the problem, use the appropriate mathematical tools to solve the problem, and interpret the results of the problem (Moschkovich, 2012). 2.3 Adjustment for ESL students

With all the challenges that ESL students face during the process of learning English, college instructors have managed to find ways to simplify mathematical word problems. It has been recommended that instructors survey the students in advance in order to gain information about their educational background, experience with math, and their language history (Moschkovich, 2012). Based on the gathered information, instructors are better able to provide the class with the appropriate curriculum, instruction, and problems in order to facilitate the success of each 
student. Studies have suggested that instructors should focus on the literacy of the students and apply this knowledge of student literacy by communicating more slowly and intentionally for ESL students to have the opportunity to clearly understand the topic being discussed (Warren et al., 2014). Others have focused on developing a strong mathematical vocabulary to enhance students' learning experiences (Smart et al., 2008). In addition, some institutions have created small classroom sizes to ensure that students obtain the appropriate attention from the instructor, which enables the instructor to focus on each student's weaknesses. In larger classrooms, students may not be given individualized attention needed to facilitate optimal learning due to the ratio of students to instructors. The aforementioned strategies should be considered in order to develop a wholistic approach to ESL students' mathematical learning. Beyond this, more strategies and techniques should be developed to encourage the success of ESL students in college and university math courses.

\section{Purpose}

The purpose of this study is to investigate the difference, if any, in performance between ESL students and native English-speaking (ENS) students in an introductory level statistics course at the University of Northern Colorado (UNC). An ESL student is classified as a student who resides in an English-speaking country or environment and whose primary language is a language other than English. Many of these students require additional English language support in order to be successful in an English learning environment.

This study was conducted in order to gain a better understanding of the performance of students in the STAT 150 course at UNC. The information gained in this study stands to benefit UNC's

Mathematical Sciences Department as well as the Applied Statistics and Research Methods Department by providing efficient measurements of performance of ESL and ENS students. Information gathered from students who have been enrolled in STAT 150 over the last five years is used to understand differences in performance between ESL and ENS students. This study may help UNC to not only understand the differences in performance among students, but it may also be referred to for decision making purposes as the university seeks to give support to ESL students. The following research question guided the study:

RQ: Have ESL students successfully completed STAT 150 (operationally, receive a final grade of an "A" or "B") at the same rate as ENS students, controlling for year, term, and student class level (i.e., Freshman, Sophomore, Junior, Senior)?

\section{Methods \& Data Description}

In order to address the research question, nonidentifiable STAT 150 student outcome data were obtained from the UNC Office of Institutional Reporting and Analysis. This dataset provided the year and term (Fall 2013 - Spring 2018, omitting Summer sessions), the final letter grade (if plus/minus grading was used, these grades were recategorized to the letter itself, omitting the plus/minus distinction), student class level (only students with an undergraduate 
classification were included), a student's nation of citizenship (if provided), and an indicator identifying ESL status (if provided) for each student. The total number of student records used in this analysis was $N=6259$, of which $n_{E S L}=102$ were considered ESL students.

STAT 150 , as an introductory mathematics course, has traditionally had a low proportion of students receiving a failing grade. Figure 1 shows the letter grade distribution for ENS and ESL students, respectively. As shown in both figures there is right skewness, which was to be expected. However, for ESL students, there is a higher proportion of " $\mathrm{C}$ " final grades than what was observed for ENS students.
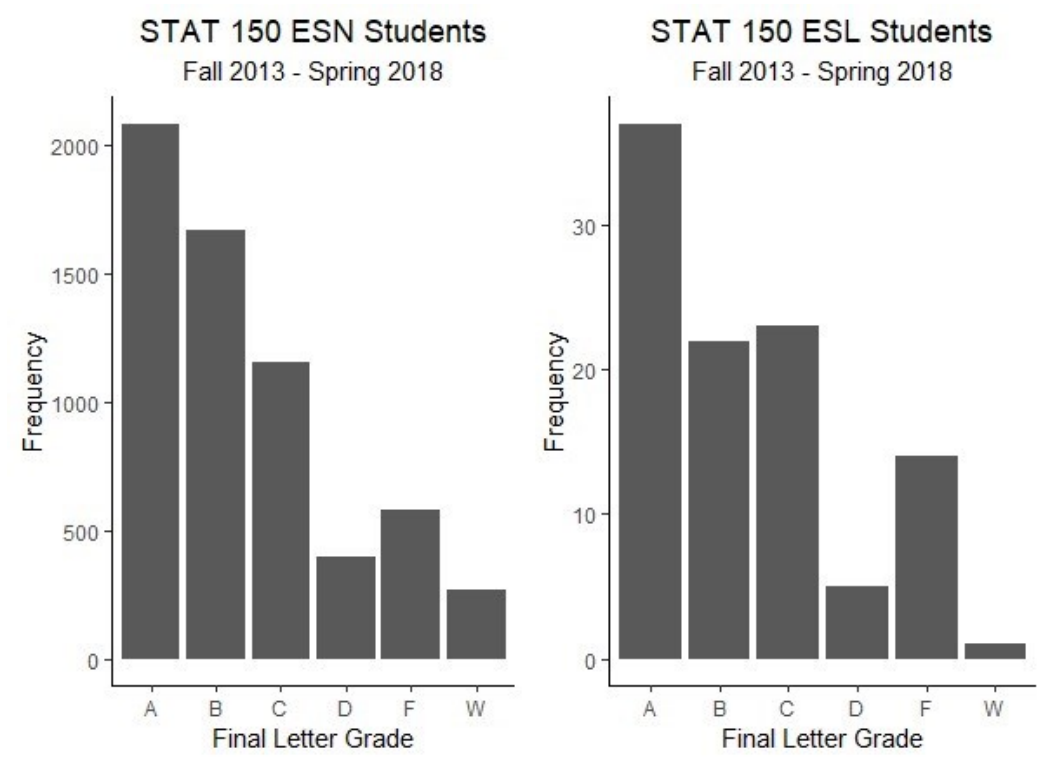

Figure 1. Final Letter Grade Distributions for ESL and ENS STAT 150 Students

In order to address the primary research question, the dichotomous, categorical nature of the response variable (earning an "A" or "B" in STAT 150 as opposed to not earning an "A" or "B") lends itself well to a logistic regression model. In a logistic regression, the natural logarithm of the odds ratio is the response variable for which the linear combination of independent variables model. In this study for example, the odds ratio is defined as the probability of a student earning an "A" or "B" divided by the probability of a student not earning those grades, and often referred to as the "logit") Given the other independent variables mentioned previously, the model to be fit is mathematically represented by Equation 1 . Here, $\pi_{i}$ represents the probability of a student earning an "A" or "B," $\beta_{0}$ represents the intercept of this linear model, and $\beta_{1} \ldots \beta_{6}$ represent the statistical effect a particular independent variable has upon the logit. Note, the ESL status of student $i$ is a dummy variable where a value of " 1 " denotes an ESL student, and a value of "0" denotes an ENS student (that is, ENS student status is the reference group). Student Classification (Freshman status is the reference group) was dummy coded similarly, as was Term (Fall is the reference group). Further, while these data are longitudinal in nature, the students enrolled in STAT 150 from semester to semester are almost certainly different students, and therefore, it is reasonable to assume the grade a student earned 
in one semester has no bearing on the grade a student in a different semester earned. Because of this, a longitudinal model was deemed unnecessary for these analyses.

$\pi^{\mathrm{i}}$

$\ln \left(1_{-}-\pi_{\mathrm{i}}\right)=\beta_{0}+\beta_{1}(\text { ESL })_{i}+\beta_{2}(\text { Sophomore })_{i}+\beta_{3}(\text { Junior })_{i}+\beta_{4}(\text { Senior })_{i}+\beta_{5}(\text { Year })_{i}+$ $\beta_{6}($ Spring $)$.

Fitting this model is a straightforward process and was performed in the statistical software program R version 3.5.1 (R Core Team, 2018). However, one problem arising from the data structure was the large differences in sample sizes between ENS and ESL students. ESL students represented $1.63 \%$ of the sample. Therefore, performing the analysis with such a sample size discrepancy may not be the most appropriate approach. Consequently, justification was given for using the computer technique referred to as "bootstrapping" to handle this problem.

Rizzo (2008) describes bootstrapping as "a class of nonparametric Monte Carlo methods that estimate the distribution of a population by resampling." Here, the distributions desired to be estimated are those of the logistic regression coefficients and their respective p-values. To perform a bootstrap analysis, ENS observations were randomly sampled from each of the observed terms (again, excluding summer terms) such that the number of sampled ENS students matched the number of ESL students in a given term. Table 1 gives the sample sizes for ESL students for each of the terms. Multiplying each of the values given in Table 1 by two and summing those products gives the effective sample size used in the logistic regression $(n=$ 184). Because the performance of this procedure in a single iteration is an ineffective use of the rich dataset obtained, the random sampling procedure for ENS students was iteratively performed $B=10,000$ times. That is, 10,000 datasets of size $n=184$ were created, and a logistic regression model, as described by Equation 1, was fit. More practically, the bootstrapping technique is justified as one could easily envision a case where the randomly selected ENS students happened to all be excellent students or all happened to be poor students. In either case, the coefficient estimates and their associated p-values may be extreme in either direction away from the true values. Reliance upon the results from a single iteration are therefore not justified, and the bootstrapping method is a more effective use of the data obtained. All coefficients and their respective p-values for each of the 10,000 datasets were stored, and the mean values were taken to be the estimates of the coefficients and p-values, respectively. Since these mean values were obtained via random sampling, the mean coefficient estimates and the mean p-value estimates can be considered random variables themselves. As a result, inference can be made directly upon p-values themselves.

Table 1. Sample Sizes for STAT 150 ESL Students for Each Term

\begin{tabular}{lllllllllll}
\hline \multirow{2}{*}{ Term } & Fall & Spring & Fall & Spring & Fall & Spring & Fall & Spring & Fall & Spring \\
& 2013 & 2014 & 2014 & 2015 & 2015 & 2016 & 2016 & 2017 & 2017 & 2018 \\
\hline Sample Size & $\mathrm{n}=6$ & $\mathrm{n}=10$ & $\mathrm{n}=17$ & $\mathrm{n}=4$ & $\mathrm{n}=10$ & $\mathrm{n}=7$ & $\mathrm{n}=13$ & $\mathrm{n}=7$ & $\mathrm{n}=10$ & $\mathrm{n}=8$ \\
\hline
\end{tabular}




\section{Results and Discussion}

Using the techniques described in the previous section, estimates for each of the coefficients and their respective p-values were obtained, and the results are shown in Table 2. As shown, none of the independent variables approached significance at the traditional $\alpha=0.05$ level. However, the senior indicator variable was estimated to be near the $\alpha=0.10$ level. As mentioned, these estimates themselves can be treated as random variables upon which inferential tests can be performed. Thus, it is of interest to determine if the senior indicator variable's p-value differs significantly from $\alpha=0.10$. However, as shown in Figure 2, it cannot be reasonably assumed that the variable is normally distributed, as is a fundamental assumption in a classical t-test, the more appropriate nonparametric Wilcoxon Signed Rank Test was performed upon the bootstrapped estimates. The results of this test are shown in Table 3. These results do give significant evidence to suggest that the true p-value for the senior indicator variable may be larger than 0.10 , which would coincide with the classical conclusion typically inferred from the results in Table 2 . While perhaps not statistically significant, this finding is still interesting albeit not surprising. As senior level students have had more exposure to collegiate coursework than their freshman counterparts, it is reasonable to assume this may be advantageous, and perhaps lead to preferable final grade outcomes.

Practically, the results of this analysis, with respect to the research question, suggest that ESL students who have been enrolled in STAT 150 at UNC are just as likely to receive a high mark in the course as ENS students. This suggests that the level of instruction and quality of content provided to all students, but specifically to ESL students, has allowed them the opportunity to develop the high levels of mathematical understanding necessary for success in the course. These broad, outcome-centric results reflect well upon the overall quality of instruction and upon UNC's English proficiency policies.

Table 2. Bootstrapped Logistic Regression Results

\begin{tabular}{lcccc}
\hline Independent Variable & Coefficient Estimate & Standard Error & Wald Test Statistic & p-value \\
\hline Intercept & 281.12 & 563.55 & 0.50 & 0.31 \\
ESL & -0.19 & 1.44 & -0.13 & 0.55 \\
Sophomore & 0.52 & 0.83 & 0.63 & 0.26 \\
Junior & 0.42 & 1.70 & 0.25 & 0.40 \\
Senior & 0.99 & 0.84 & 1.19 & 0.12 \\
Year & -0.14 & 0.28 & -0.50 & 0.31 \\
Spring & 0.02 & 0.10 & 0.22 & 0.59 \\
\hline
\end{tabular}




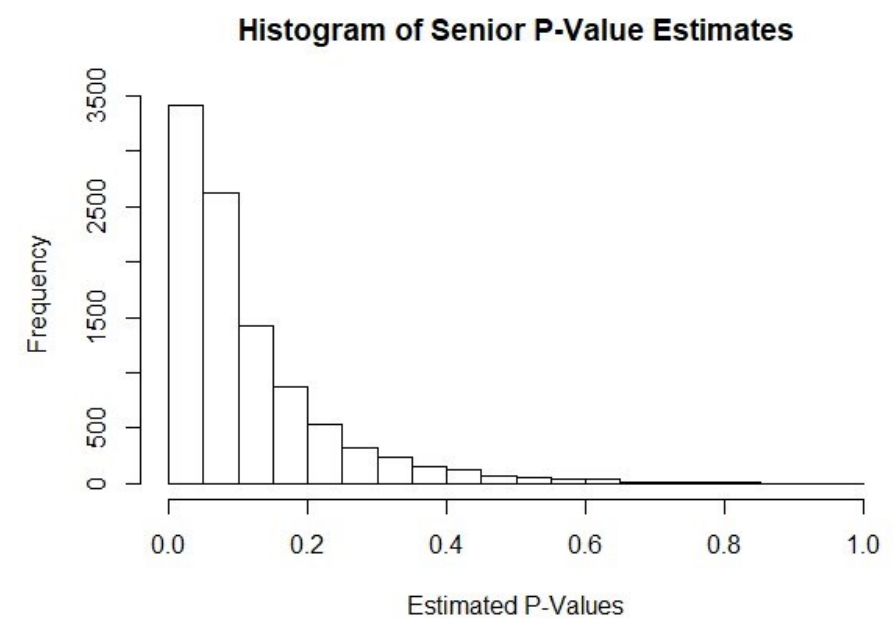

Figure 2. Histogram of Senior Indicator Variable P-Value Estimates

Table 3. Results of Wilcoxon Signed Rank Test on Senior Indicator Variable

\begin{tabular}{lc}
\hline Results of Wilcoxon Signed Rank Test on Senior Indicator Variable \\
\hline Wilcoxon Test Statistic & 23180000 \\
p-value & $<0.0001$ \\
\hline
\end{tabular}

\section{Limitations \& Future Directions}

As is the case in all research, this study had limitations. First, because there were so few ESL students enrolled in STAT 150 in each of the sampled terms, it is difficult to detect statistical differences with traditional inference techniques. The bootstrapping technique certainly mitigated some of this problem, but it cannot increase the number of ESL student observations. Second, this analysis only considered the most recent 10 semesters worth of data. While the recency of the observations is desirable, the data analyzed may not necessarily be indicative of broader and historical ESL student success in STAT 150 at UNC. Third, the literature review highlighted the importance of instructor quality in ESL student success. In this study, while we can broadly conclude that instructor quality has been sufficient, it would be of value going forward to account for the effect a particular instructor may have on ESL student outcomes. Finally, this study only considered letter grade outcomes as the measure of success for ESL students. It may be of value to obtain ESL student perceptions of the STAT 150 course through qualitative analysis. This could allow a greater understanding of what broad, non-quantifiable characteristics of instruction and material presentation lead to either positive or negative letter grade outcomes. Additionally, in this study, positive student outcomes were operationally defined as earning an "A" or "B" letter grade in the course. However, anecdotally, it is known that some students who earn a " $C$ " in a course may have felt they were successful in the course while others may consider only an "A" successful. Therefore, using a different measure of student success in a course besides final letter grade may be of value in future studies. 


\section{References}

Abedi, J., Courtney, M., Leon, S., Kao, J., \& Azzam, T. (2006). English language learners and math achievement: A study of opportunity to learn and language accommodation (CSE Report 702). Los Angeles: University of California, Los Angeles. National Center for Research on Evaluation, Standards, and Student Testing (CRESST). Retrieved from http://cresst.org/publications/cresst-publication-3073/

Al-jamal, D., \& Miqdadi, R. (2013). Mathematical Problem Solving Strategies in Plain English. Journal of Education and Practice, 4(11).

Ewing, K., \& Huguelet, B. (2009). The English of Math - It is not just numbers. Authenticity in the Language Classroom and Beyond: Adult Learners: TESOL Classroom Practice Series, eds.

Finn, H. B. (2018). Articulating struggle: ESL students' perceived obstacles to success in a community college writing class. Journal of Second Language Writing. https://doi.org/10.1016/j.jslw.2018.09.001

Gurin, P., Dey, E., Hurtado, S., \& Gurin, G. (2002). Diversity and higher education: Theory and impact of educational outcomes. Harvard Educational Review, 72(3), 330-366. https://doi.org/10.17763/haer.72.3.01151786u134n051

Hakuta, K., Butler, Y. G., \& Witt, D. (2000). How long does it take English learners to attain proficiency? (Policy Report 2000-1). Santa Barbara, CA: University of California Linguistic Minority Research Institute. Retrieved from https://web.stanford.edu/ hakuta/Publications/\%282000\%29\%20-\%20HOW\%20LONG \%20DOES\%20IT\%20TAKE\%20ENGLISH\%20LEARNERS\%20TO\%20 ATTAIN\%20PR.pdf

Krick-Morales, B. (2017). Reading and Understanding Written Math Problems. Retrieved from

http://www.colorincolorado.org/article/reading-and-understanding-written-math-proble $\mathrm{ms}$

Langeness, J. (2011). Methods to improve student ability in solving math word problems (Unpublished master's thesis).

Meiers, M., \& Trevitt, J. (2010). The digest edition 2010/2: Language in the mathematics classroom. The Digest, NSWIT, 2010(2). Retrieved from http://research.acer.edu.au/digest/8

Moschkovich, J. N. (2012). Mathematics, the Common Core, and language: Recommendations for mathematics instruction for ELLs aligned with the Common Core. Proceedings of the Understanding Language conference. Stanford, CA: Stanford University. Retrieved from http://ell.stanford.edu/publication/mathematics-common-core-and-language

Nelson, C. E. (1996). Student diversity requires different approaches to college teaching, even in math and science. American Behavioral Scientist, 40(2), 165-175. 
https://doi.org/10.1177/0002764296040002007

R Core Team. (2018). R: A language and environment for statistical computing. $R$ Foundation for Statistical Computing, Vienna, Austria. Retrieved from https://www.R-project.org/

Redd, Z., Cochran, S., Hair, E., \& Moore, K. (2002). Academic achievement programs and youth development: A synthesis. Washington, DC: Child Trends. https://doi.org/10.1037/e315372004-001

Rizzo, M. L. (2008). Statistical Computing with R. Boca Raton, FL: Chapman \& Hall.

Smart, D., Sanson, A., Baxter, J., Edwards, B., \& Hayes, A. (2008). Home-to-school transitions for financially disadvantaged children: Final report. Sydney, NSW: The Smith Family. Retrieved from https://www.thesmithfamily.com.au/-/media/files/research/reports/home-school summary2008.pdf?la=en\&hash=07E6BAA562B1F8EBEC14653C5308E0E9

Warren, E., Harris, K., \& Miller, J. (2014). Supporting young ESL students from disadvantaged contexts in their engagement with mathematics: Teachers' pedagogical challenges. International Journal of Pedagogies and Learning, 9(1), 10-25. https://doi.org/10.1080/18334105.2014.11082016

\section{Copyright Disclaimer}

Copyright for this article is retained by the author(s), with first publication rights granted to the journal.

This is an open-access article distributed under the terms and conditions of the Creative Commons Attribution license (http://creativecommons.org/licenses/by/3.0/). 